Pesq. Vet. Bras. 37(5):511-515, maio 2017

DOI: $10.1590 / \mathrm{S} 0100-736 \mathrm{X} 2017000500014$

\title{
Estudo retrospectivo da casuística de curicacas (Theristicus caudatus) recebidas pelo Projeto de Atendimento a Animais Selvagens do Planalto Catarinense no período de 2003-2014 ${ }^{1}$
}

\author{
Eloisa C. Bach ${ }^{2}$, Adson Costa ${ }^{2}$, Bruno Lunardeli², Maria Helena M. Baldni' ${ }^{2}$, Nilson \\ Oleskovicz ${ }^{3}$, Renata A. Casagrande ${ }^{4 *}$ e Aury N. de Moraes ${ }^{3}$
}

\begin{abstract}
Bach E.C., Costa A., Lunardeli B., Baldni M.H.M., Oleskovicz N., Casagrande R.A. \& Moraes A.N. 2017. [Retrospective study of cases of Buff-necked Ibis (Theristicus caudatus) treated by the veterinary care project of wild animals of Santa Catarina plateau during the years 2003-2014.] Estudo retrospectivo da casuística de Curicacas (Theristicus caudatus) recebidas pelo Projeto de Atendimento a Animais Selvagens do Planalto Catarinense no período de 2003-2014. Pesquisa Veterinária Brasileira 37(5):511-515. Hospital de Clínicas Veterinárias, Centro de Ciências Agroveterinárias, Universidade do Estado de Santa Catarina, Av. Luiz de Camões 2090, Lages, SC 88520-000, Brazil. E-mail: a2anm@cav.udesc.br

This paper describes a retrospective study of all cases of Buff-necked Ibis (Theristicus caudatus) treated by the veterinary care project of wild animals of Santa Catarina plateau during the years 2003 to 2014. In this period 77 Buff-necked Ibis were treated, all of them were free living animals from Santa Catarina plateau. It was found that, $33.7 \%$ were young animals, $16.8 \%$ were adults and $49.5 \%$ indeterminate age. About these animals, $22.1 \%$ were males, $14.3 \%$ were females and the other ones undefined. About the clinical disorders, $55.8 \%$ had bone fracture, 9.1\% demonstrated neurological disorders, 3.9\% multiples lacerations in skin and muscles, 3.9\% demonstrated dislocation of member $3.4 \%$ demonstrated oral bleeding. Air sac rupture was observed in $2.6 \%$ of the animals, $2.6 \%$ were dyspneic and $2.6 \%$ had diarrhea, $1.3 \%$ peritonitis. In $20.8 \%$ of the cases the animal only demonstrated unspecific signs such as malnutrition. Of the animals treated, 55.8\% came to death, $28.6 \%$ were euthanized, $5.2 \%$ were treated an sent to IBAMA or to a sorting center for wild animals. $2.6 \%$ were released into the wild, and in $7.8 \%$ of the cases de destination was not informed. Necropsy was performed in $70.8 \%$ of the animals, wherein $82.6 \%$ of those birds had came to a definitive diagnosis of trauma and in $2.2 \%$ the diagnosis was peritonitis caused by a gizzard perforation by a metallic foreign body. And $2.2 \%$ came to death for pneumonia caused by a foreign body (projectile). The high mortality of birds may be related with the severity of the lesions and with disorders resulting from trauma. The buff-necked ibis was the specie that presented the highest number of treatment by this project during the period described in the study. This information demonstrated that studding the disorders of this bird can serve as an indicator of the the risk which other bird species in the region are suffering.
\end{abstract}

INDEX TERMS: Buff-necked Ibis, Theristicus caudatus, case studies, diagnosis, Santa Catarina plateau.

RESUMO.- 0 presente trabalho descreve um estudo retrospectivo da casuística de Curicacas (Theristicus caudatus) atendidas pelo Projeto de Atendimento Médico Veterinário

\footnotetext{
${ }^{1}$ Recebido em 17 de agosto de 2015.

Aceito para publicação em 11 de agosto de 2016.

${ }^{2}$ Médicos Veterinários, Mestrandos do Programa de Pós-Graduação Ciência Animal do Centro de Ciências Agroveterinárias, Universidade do Estado de Santa Catarina (CAV/UDESC), Av. Luís de Camões 2090, Bairro Conta Dinheiro, Lages, SC 88520-000, Brasil.
}

a Animais Selvagens do Planalto Catarinense (CAV/UDESC) nos anos de 2003-2014. Neste período foram atendidas 77 curicacas, todas de vida livre e do Planalto Catarinen-

\footnotetext{
${ }^{3}$ Médicos Veterinários, Docente do Hospital de Clínica Veterinária (HCV), CAV/UDESC, Av. Luís de Camões 2090, Bairro Conta Dinheiro, Lages, SC 88520-000, Brasil.

${ }^{4}$ Médica Veterinária, Professora Doutora do Laboratório de Patologia Animal e Aviária, CAV/UDESC, Av. Luís de Camões 2090, Bairro Conta Dinheiro, Lages, SC 88520-000, Brasil.*Autor para correspondência: a2anm@cav.udesc.br
} 
se. Constatou-se que $33.7 \%$ eram jovens, $16,8 \%$ adultas e 49,5\% com idade indeterminada. Dessas, $22.1 \%$ eram machos, $14.3 \%$ fêmeas e os demais indefinidos. Em relação às afecções clínicas, $55.8 \%$ possuíam fr,tura óssea, 9,1\% sinais neurológicos, 3,9\% múltiplas lacerações na pele e músculos, 3,9\% luxação em membro, 3,\% hemorragia em cavidade oral, $2,6 \%$ ruptura de sacos aéreos, $2,6 \%$ dispneia, $2,6 \%$ diarreia e 1,3\% peritonite. Em 20,8\% dos casos apresentavam apenas sinais inespecíficos como desnutrição. Dos animais atendidos, 55,8\% morreram; 28,6\% foram eutanasiados; $5,2 \%$ tratados e encaminhados à sede do IBAMA ou CETAS; 2,6\% realizou-se soltura e em 7,8\% o destino não foi informado. Efetuou-se necropsia em $70,8 \%$, sendo que em $82,6 \%$ dessas obteve-se o diagnóstico definitivo de traumatismo e em $2,2 \%$ o diagnóstico foi de peritonite secundária a perfuração de moela por corpo estranho metálico e 2,2\% vieram a óbito por pneumonia causada por corpo estranho (projétil). A alta mortalidade das aves atendidas parece estar relacionada com a gravidade das lesões apresentadas e afecções secundárias aos traumatismos. A curicaca foi a espécie que apresentou o maior número de atendimentos pelo projeto durante o período descrito no estudo, demonstrando que o estudo da casuística dessa ave pode servir como indicador do risco a que outras espécies de aves da região estão sujeitas.

TERMOS DE INDEXAÇÃO: Curicacas, Theristicus caudatus, casuística, diagnóstico, planalto catarinense.

\section{INTRODUÇÃo}

Sick (1984) descreveu a curicaca (Theristicus caudatus) como pertencente à ordem Ciconiiformes e família Threskiornithidae. A ordem Ciconiiformes foi recentemente revista após estudos moleculares, com a inclusão das famílias Ardeídae e Threskiornithidae em Pelecaniformes (Fontenelle \& Barros 2014). Esta ave apresenta o bico longo e curvo; dorso cinzento-claro, com brilho esverdeado, rêmiges e retrizes pretas; parte das coberteiras superiores das asas é esbranquiçada, formando uma mancha clara no lado superior da asa (Fig.1), visível durante o voo (Matheu \& Hoyo 1992). Nesta espécie não há dimorfismo sexual e o macho costuma ser levemente maior que a fêmea, atingindo $69 \mathrm{~cm}$ de comprimento e cerca de $43 \mathrm{~cm}$ de envergadura (Sick 1984). Estes animais têm hábitos diurnos a crepusculares, andam abertamente nos campos secos, e alimentam-se de gafanhotos, aranhas, centopéias, lagartixas, cobras e ratos (Rosário 1996). Os Ciconiiformes e os Pelecaniformes geralmente são carnívoros aquáticos e ingerem peixes, anfíbios, insetos aquáticos, moluscos e pequenos mamíferos, aves e répteis. Em cativeiro são mantidos a base de peixes, carne moída, insetos, minhocas e rações comerciais para animais domésticos (Fontenelle \& Barros 2014).

Esta ave tem distribuição geográfica por toda a América do Sul, sendo que no Brasil encontram-se principalmente nas regiões Sul, Sudeste e Centro-Oeste, habitando pastagens, campos secos e alagados (Sick 1984). A espécie está classificada como Pouco Preocupante (Least Concern - LC) segundo os critérios da International Union for Conservation of Nature (IUCN), devido a tendência da população ser aparentemente estável, e que, portanto, a espécie não se apro- xima dos limiares de vulnerável sob o critério tendência populacional ( $>30 \%$ declínio ao longo de dez anos ou três gerações) (BirdLife International 2012). No estado de Santa Catarina esta ave habita a Mata e Campos de Araucária, a Mata Atlântica e a Mata Subtropical do Rio Uruguai (Rosário 1996). Nos últimos anos houve relatos da visualização desta espécie na Ilha de Santa Catarina, no município de Florianópolis e no município de Celso Ramos, bem como no Oeste do Estado, onde a cerca de 20 anos atrás não havia relato (Ghizoni-Jr \& Kunz 2006). Nota-se a preferência de construir seus ninhos em araucárias, onde também se reúnem ao entardecer para dormir (Rosário 1996, Oliveira 2008). No ambiente natural, por ocasião do período reprodutivo, muitos Pelecaniformes das famílias Ardeidae e Threskiornithidae reúnem-se em colônias reprodutivas ou ninhais.

0 objetivo deste trabalho é relatar as curicacas recebidas no Projeto de Atendimento a Animais Selvagens do Planalto Catarinense do Centro de Ciências Agroveterinárias da Universidade do Estado de Santa Catarina (CAV/ UDESC), descrevendo as principais alterações clinico-patológicas observadas, bem como as causas de morte.

\section{MATERIAL E MÉTODOS}

Um estudo retrospectivo da casuística de curicacas (Theristicus caudatus) recebidas no Projeto de Atendimento a Animais Selvagens do Planalto Catarinense do CAV/UDESC foi efetuado abrangendo o período de 2003 a 2014. Foram avaliados os históricos e fichas clínicas (origem dos animais, motivo do internamento, tratamento, destino) de todas as curicacas (Theristicus caudatus) atendidas durante esse período, bem como os laudos anatomopatológicos efetuados pelo Laboratório de Patologia Animal (CAV/ UDESC).

Quanto à determinação da idade das aves, esta foi efetuada pela observação do tamanho, tipo de plumagem, coloração da íris e membros pélvicos. As curicacas não apresentam dimorfismo sexual, assim a determinação do sexo foi efetuada nos animais em que se realizou necropsia e dois deles foram sexados por meio de teste de DNA utilizando-se amostras de sangue. Todos estes dados foram agrupados e compilados.

\section{RESULTADOS}

No período de 2003-2014 no Projeto de Atendimento a Animais Selvagens do Planalto Catarinense foram atendidas 502 aves selvagens de 53 diferentes espécies, sendo a curicaca a espécie mais prevalente, totalizando $15.3 \%$ (77/502) dos casos. A distribuição dos atendimentos nesta espécie de acordo com o mês e o ano no decorrer deste período está representada na Figura 2. 0 maior número de atendimentos ocorreu entre os meses de agosto e dezembro, sendo que esse período abrange $78,7 \%$ de todos os atendimentos.

Todas as curicacas avaliadas eram de vida livre, dessas, 40,3\% (31/77) oriundas do município de Lages, 3,9\% (3/77) de Correia Pinto, 2,6\% (2/77) de Painel, 2,6\% (2/77) de Ponte Alta e em 50,6\% (39/77) dos casos não havia informação na ficha clínica do município, no entanto relatava-se que todas estas pertenciam ao Planalto Catarinense. Das aves atendidas, 48\% (37/77) foram encaminhadas pela Polícia de Proteção Ambiental, 23,4\% (18/77) por pessoas da comunidade, $2,6 \%(2 / 77)$ pela sede do IBAMA 


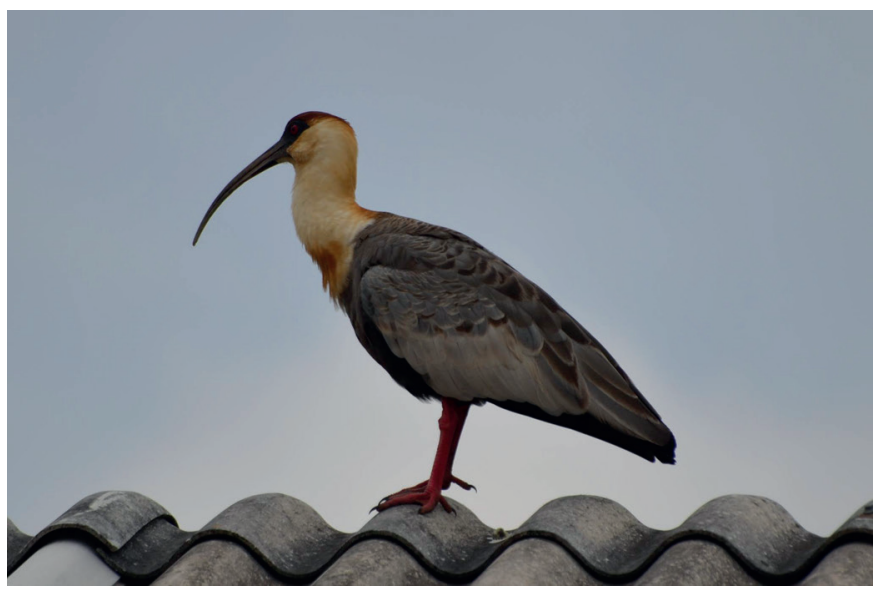

Fig.1. Exemplar de curicaca (Theristicus caudatus) na região de Lages, Santa Catarina.

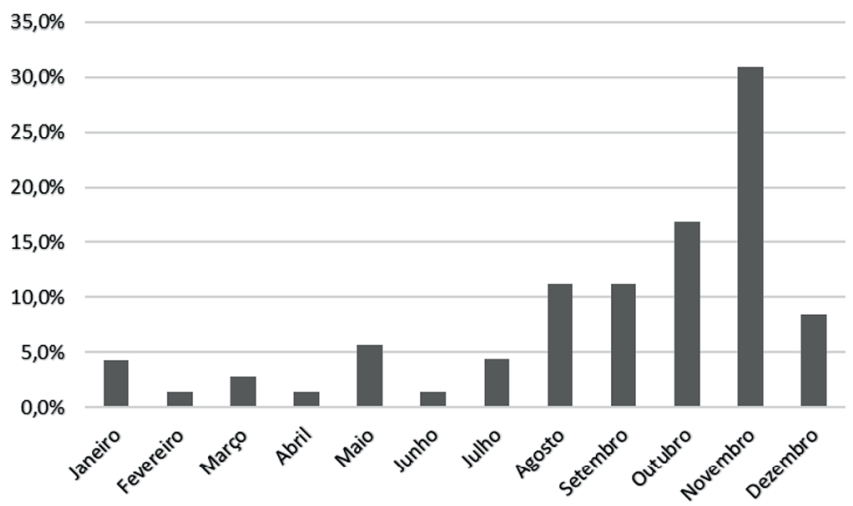

Fig.2. Porcentagem de curicacas (Theristicus caudatus) atendidas pelo Projeto de Atendimento Médico Veterinário de Animais Silvestres do Planalto Catarinense, entre o período de 20032014, distribuídas entre meses do ano.

em Painel/ SC, 1,3\% (1/77) pelo Corpo de Bombeiros, e em $24,6 \%(19 / 77)$ das fichas avaliadas não constava essa informação.

Às causas do encaminhamento destas aves ao projeto foram: $26 \%$ (20/77) encontradas com impossibilidade de voo, 15,5\% (12/77) no interior de residências, 4\% (3/77) por queda de ninho, 2,6\% (2/77) sofreram atropelamento, $2,6 \%(2 / 77)$ atacadas por cães, $1,3 \%(1 / 77)$ possuía as penas sujas de óleo, 1,3\% (1/77) foi alvejada por projétil, $1,3 \%(1 / 77)$ eletrocussão e em 45,5\% (35/77) dos casos não foi informada a causa do encaminhamento.

Com relação a faixa etária constatou-se que 33,8\% (26/77) eram jovens; 16,9\% (13/77) adultas; e em 49,3\% (38/77) esta informação não constava na ficha. Dos animais recebidos, $22,1 \%$ (17/77) eram machos, $14,3 \%$ (11/77) fêmeas e os demais indefinidos 63,6\% (49/77).

Em relação as afecções clínicas destes animais, 55,8\% (43/77) possuíam fratura óssea, sendo $37,2 \%(16 / 43)$ no tibiotarso, 23,2\% (10/43) no úmero, 23,2\% (10/43) no rádio e ulna, $11,7 \%$ (5/43) no fêmur, $11,7 \%$ (5/43) no metacarpo (Fig.3), 2,3\% (1/43) no crânio e 2,3\% (1/43) no bico. Destes animais apenas 23,3\% (10/43) foram submetidos ao tratamento cirúrgico, sendo sete cirurgias de osteossíntese, duas amputações de metacarpo e uma reconstrução de bico.

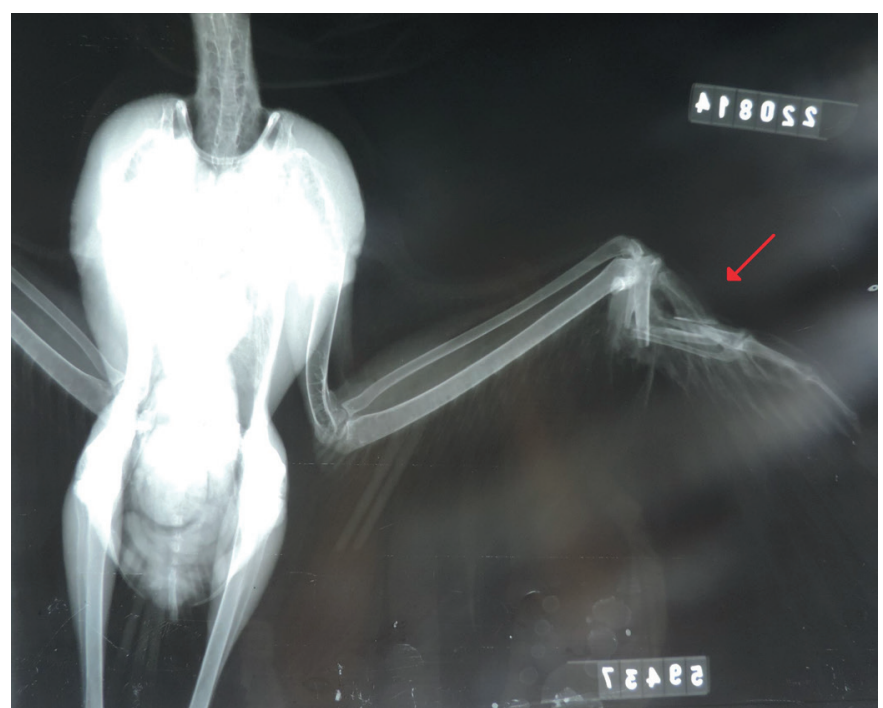

Fig.3. Imagem radiográfica de uma curicaca (Theristicus caudatus) apresentando fratura de metacarpos esquerdos (seta).

Dos demais casos, 9,1\% (7/77) possuíam sinais neurológicos caracterizados por incoordenação, 3,9\% (3/77) exibiam múltiplas lacerações na pele e nos músculos peitorais, asas e membros pélvicos, 3,9\% (3/77) apresentavam luxação em membro sendo que uma ave apresentava luxação coxofemoral e duas escapulo-umeral, 3,9\% (3/77) apresentavam hemorragias em cavidade oral, 2,6\% (2/77) apresentavam ruptura de sacos aéreos, 2,6\% (2/77) estavam dispneicos, 2,6\% (2/77) apresentavam diarreia e $1,3 \%$ (1/77) peritonite. Em 20,8\% (16/77) não se estabeleceu um diagnóstico definitivo, chegaram apresentando apenas desnutrição ou nenhuma alteração perceptível ao exame físico.

Quanto a alimentação fornecida aos animais atendidos, inicialmente a dieta consistia de minhocas e papas para alimentação de aves, feita com uma fonte de proteína de origem animal (ração de cães, peixe in natura ou albumina), água e vegetais, que era realizado por sonda esofágica em caso de anorexia, porém havia dificuldade de conseguir minhocas em quantidade suficiente. Além disso muitas curicacas, principalmente filhotes debilitados regurgitavam a papa oferecida e em certas ocasiões o conteúdo era aspirado para os pulmões e sacos aéreos. No último ano tem se conseguido bons resultados em adaptar e manter a alimentação dos animais com carne de frango enriquecida com suplementos próprios para a alimentação animal, os animais são adaptados à dieta com alimentação forçada de pequenos pedaços, e aos poucos são incentivados a se alimentar sozinhos.

Dos animais atendidos, $55.8 \%$ (43/77) vieram a óbito durante o tratamento, em $28.6 \%$ (22/77) dos casos foi realizada eutanásia, 5.2\% (4/77) foram tratados e encaminhados à sede do IBAMA e a um Centro de Triagem de Animais Silvestres, 2.6\% (2/77) dos casos realizou-se soltura e em $7.8 \%(6 / 77)$ o destino não constava na ficha.

Dos 65 animais que morreram, em 70,8\% (46/65) efetuou-se a necropsia. Em 82,6\% (38/46) destas obteve-se o diagnóstico definitivo de traumatismo, caracterizada por múltiplas fraturas ósseas, além de hemorragia cerebral de- 


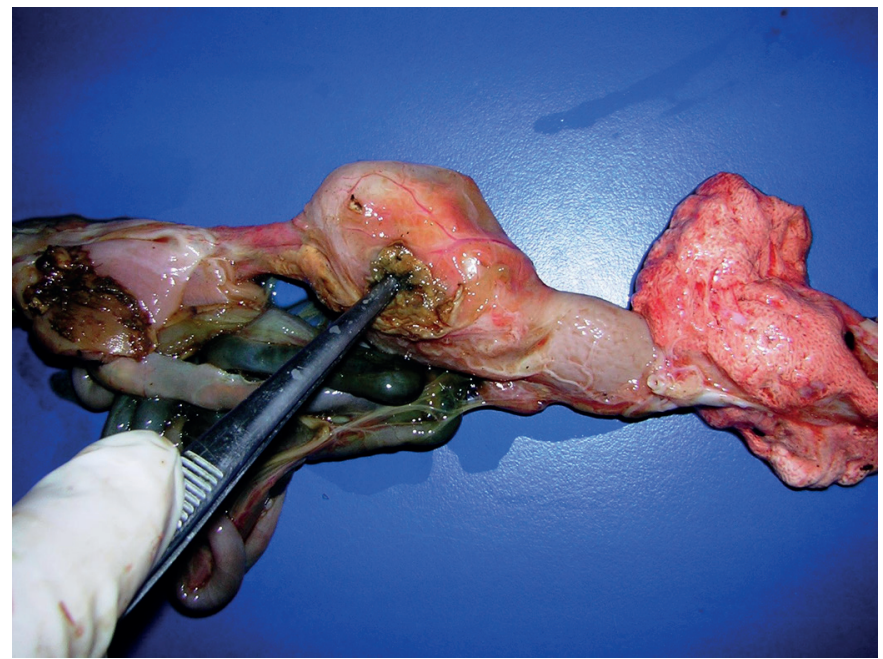

Fig.4. Perfuração em ventrículo de curicaca (Theristicus caudatus) por corpo estranho.

corrente de trauma cranioencefálico $(5 / 46)$ e ruptura completa de traqueia (1/46). Em 2,2\% (1/46) o diagnóstico foi de peritonite secundária a perfuração de ventrículo (moela) por corpo estranho metálico (Fig.4), em 2,2\% (1/46) houve pneumonia por corpo estranho (projétil) e em $13 \%$ (6/46) não houve conclusão anatomopatológica.

À necropsia evidenciou-se também que 19,6\% (9/46) das aves estavam caquéticas. Observou-se que 10,9\% (5/46) das curicacas possuíam corpo estranho no aparelho digestório, que tratava-se de material plástico no papo $(1 / 5)$, fragmentos de vidro no proventrículo $(1 / 5)$, material metálico pontiagudo na moela (1/5), fragmentos de vidro e metal na moela $(1 / 5)$ e material plástico no intestino delgado (1/5). Evidenciaram-se ainda fragmentos de projéteis (chumbo) alojados na musculatura de 4,3\% (2/46) e 2,2\%(1/46) apresentava o projétil no pulmão. Essas aves também apresentavam ecto e endoparasitos, sendo que 21,7\% (10/46) possuíam piolhos da Ordem Mallophaga e em 4,3\% (2/46) havia miíase secundária a lesões traumáticas. Em 21,7\% (10/46) das aves foram encontrados nematódeos, sendo que destes $70 \%(7 / 10)$ possuíam o parasita no intestino delgado, $10 \%(1 / 10)$ no proventrículo; $10 \%$ $(1 / 10)$ no intestino grosso e em $10 \%(1 / 10)$ no proventrículo, na moela e no intestino delgado. Platelmintos foram observados no intestino delgado de 4,3\% (2/46) das aves e $8,7 \%(4 / 46)$ apresentavam múltiplos pontos brancos em pleura e em musculatura identificados como ácaros. Dos parasitos encontrados não foram localizados as suas classificações, para melhor detalhamento.

\section{DISCUSSÃO E CONCLUSÕES}

Existem poucos estudos e relatos sobre as afecções que acometem as curicacas no Brasil, dentre eles o trabalho de Pinto \& Vicente (1995) identificou parasitas intestinais provenientes de curicacas como pertencentes a espécie Tetrameres spirospiculum. No presente estudo observou-se que 49,3\% (38/77) vieram a óbito em decorrência de traumatismos diversos causados por atropelamento, ataques de cães, projeteis de arma de fogo dentre outros. Em um animal houve peritonite secundária a perfuração da moela por um corpo estranho metálico. Isso indica que esses espécimes viviam em um ambiente antropizado e que esse pode trazer prejuízos à saúde das curicacas. Frequentemente esses animais chegam sem um histórico completo, são encontradas debilitadas pela população e entregues ao hospital veterinário, dessa forma não é possível ter certeza de quais são os riscos mais significativos para as curicacas, porém avaliando os tipos de afecções e a idade dos animais os autores acreditam que o atropelamento e a queda dos ninhos estejam entre os fatores mais importantes que levam ao óbito para essa espécie na região do Planalto Catarinense.

Quanto ao recebimento das aves de acordo com a época do ano, a maior ocorrência foi nos meses de agosto a dezembro, sendo que esse período abrange $78,7 \%$ de todos os atendimentos realizados a essa espécie. Esta prevalência pode ter relação com período reprodutivo, que segundo Donázar et al. (1994) se estende de setembro a dezembro. Esta ave vive em pequenos grupos e costumam pôr de dois a quatro ovos, sendo que o casal reveza-se para cuidar dos filhotes, que são alimentados por regurgitação (Sick 1984). Devido a isso, este é o período de maior atividade dos pais, estando assim mais expostos aos desafios ambientais. $\mathrm{Ou}-$ tra observação importante é que um grande número de animais recebidos neste período era de jovens, provavelmente se deve ao fato desses animais caírem dos ninhos com facilidade em tempestades e ventanias ou enquanto aprendem a voar.

A alta mortalidade $(84,4 \%)$ dos animais atendidos deve estar relacionada com a gravidade das lesões que esses apresentaram quando chegaram ao Hospital Veterinário. A avaliação dos laudos de necropsia demonstrou que muitos animais apresentaram complicações concomitantes ou secundárias aos traumas quando chegam para atendimento veterinário, como desnutrição, parasitose, corpo estranho no sistema digestório entre outras. A dificuldade de manter esses animais por longos períodos em cativeiro também contribui para o alto índice de óbitos. 0 estresse e dificuldade de alimentação dessas aves são fatores significativos já que eles têm se mostrado resistentes a se alimentar sozinhos. A dificuldade de adaptar os animais de vida livre a comer alimentos industrializados pode ser uma característica importante que contribui negativamente em tratamentos prolongados em cativeiro. No entanto, nesse projeto a equipe têm conseguido bons resultados em adaptar e manter a alimentação dos animais com carne de frango enriquecida com suplementos (carbonato de cálcio e complexos vitaminicos). Através deste estudo retrospectivo pode-se constatar que no período de 2003-2014 a espécie de ave com maior número de atendimentos no Projeto de Atendimento a Animais Selvagens do Planalto Catarinense foi a curicaca. Isso demonstra que essa é uma das espécies de ave de grande importância para a região do Planalto Catarinense e a casuística reflete a condição de vulnerabilidade em que a espécie se encontra em decorrência da pressão antrópica, já que a maior parte dos animais atendidos apresentavam traumatismos $(82,6 \%$ dos animais necropsiados) e alguns casos ingestão de corpo estranho $(10,9 \%)$. 
Sendo assim, pode-se utilizá-la como sentinela ambiental e para estudar as afecções e os riscos que estão sujeitas as outras espécies de aves que habitam esta região, pois por ser uma ave conhecida pela população da região de grande porte as curicacas são resgatadas com certa frequência, e encaminhadas a atendimento veterinário, o que nem sempre ocorre com outras espécies. A região serrana do estado de Santa Catarina carece de estudos sobre a ecologia das curicacas e de muitas outras espécies de aves, porém com este estudo sugere que o contato próximo com os seres humanos pode ter um impacto negativo sobre a populações de curicacas na região.

\section{REFERÊNCIAS}

Birdlife International 2012. Theristicus caudatus. IUCN Red List of Threatened Species. Version 2014.3. Disponível em <http://www.iucnredlist. org/> Acesso em 6 May 2015.

Fontenelle J.H. \& Barros L.A. 2014. Ciconiiformes, Pelecaniformes, Gruiniformes e Cariamiformes (Maguari, Tuiuiú, Garça, Socó, Guará, Colhereiro, Jacamim, Saracura, Frango-d'Agua, Grou e Ceriema), p.441-455. In: Cubas Z.S., Silva J.C.R. \& Catão-Dias J.L. (Eds), Tratado de Animais Selvagens: medicina veterinária. Vol.1. $2^{\underline{a}}$ ed. Roca, São Paulo.
Donázar J.A., Ceballos 0., Travaini A., Rodriguez A., Funes M. \& Hiraldo F. 1994. Breeding performace in relation to nest-site substratum in a Buffnecked Ibis (Theristicus caudatus) population in Patagonia. The Condor, Washington, 96:994-1002.

Ghizoni-Jr I.R. \& Kunz T.S. 2006. Registro da curicaca Theristicus caudatus (Threskiornithidae) e do carão Aramus guaraúna (Aramidae) na Ilha de Santa Catarina, Sul do Brasil. Atualidades Ornitológicas, Iporã/PR n.134, p.12-13, 2006. Disponível em <http://www.ao.com.br/download/ A0171_50.pdf)> Acesso em 31 mar. 2015.

Matheu E. \& Del Hoyo J. 1992. Family Threskiornithidae (Ibises and Spoonbills), p.472-506. In: Del Hoy J., Eliott A. \& Sargatal J. (Eds), Handbook of the Birds of the World. Vol.1. Lynx Ediciones, Barcelona.

Oliveira A.C. 2008. Ocupação ambiental e características populacionais de curicacas Theristicus caudatus em linhas de transmissão de alta tensão. Dissertação de Mestrado em Biologia Animal, Universidade de Brasília, Brasília. 54p.

Pinto R.M. \& Vicente J.J. 1995. Tetrameres (Tetrameres) spirospiculum n. sp. (Nematoda, Tetrameridae) from the Buff-necked Ibis, Theristicus caudatus caudatus (Boddaert) (Aves, Threskiornithidae). Rio de Janeiro. Mem. Instituto Osvaldo Cruz 90( 5):615-617.

Rosário L.A. 1996. As aves em Santa Catarina: distribuição geográfica e meio ambiente. Fatma, Florianópolis. 326p.

Sick H. 1984. Ornitologia Brasileira. Vol.1. 2ª ed. Editora Universidade de Brasília, Brasília. 480p. 